\title{
The Vitamin Riboflavin and Its Derivative Lumichrome Activate the LasR Bacterial Quorum-Sensing Receptor
}

\author{
Sathish Rajamani, ${ }^{1}$ Wolfgang D. Bauer, ${ }^{1}$ Jayne B. Robinson, ${ }^{2}$ John M. Farrow, $\mathrm{III},{ }^{3}$ Everett C. Pesci, ${ }^{3}$ \\ Max Teplitski, ${ }^{4}$ Mengsheng Gao, ${ }^{4}$ Richard T. Sayre,${ }^{5}$ and Donald A. Phillips ${ }^{1}$ \\ ${ }^{1}$ Department of Plant Sciences, University of California, Davis 95616, U.S.A.; ${ }^{2}$ Biology Department, University of Dayton, \\ Dayton, OH 45469, U.S.A.; ${ }^{3}$ Department of Microbiology and Immunology, Brody School of Medicine, East Carolina University, \\ Greenville, NC 27858, U.S.A.; ${ }^{4}$ Department of Soil and Water Science, University of Florida-IFAS, Gainesville 32611-0290, \\ U.S.A.; ${ }^{5}$ Department of Plant Cellular and Molecular Biology, Ohio State University, Columbus 43210, U.S.A.
}

Submitted 25 March 2008. Accepted 13 May 2008.

\begin{abstract}
Many bacteria use quorum sensing (QS) as an intercellular signaling mechanism to regulate gene expression in local populations. Plant and algal hosts, in turn, secrete compounds that mimic bacterial QS signals, allowing these hosts to manipulate QS-regulated gene expression in bacteria. Lumichrome, a derivative of the vitamin riboflavin, was purified and chemically identified from culture filtrates of the alga Chlamydomonas as a QS signal-mimic compound capable of stimulating the Pseudomonas aeruginosa LasR QS receptor. LasR normally recognizes the $N$-acyl homoserine lactone (AHL) signal, $\boldsymbol{N}$-3-oxo-dodecanoyl homoserine lactone. Authentic lumichrome and riboflavin stimulated the LasR receptor in bioassays and lumichrome activated LasR in gel shift experiments. Amino acid substitutions in LasR residues required for AHL binding altered responses to both AHLs and lumichrome or riboflavin. These results and docking studies indicate that the AHL binding pocket of LasR recognizes both AHLs and the structurally dissimilar lumichrome or riboflavin. Bacteria, plants, and algae commonly secrete riboflavin or lumichrome, raising the possibility that these compounds could serve as either QS signals or as interkingdom signal mimics capable of manipulating QS in bacteria with a LasR-like receptor.
\end{abstract}

Additional keywords: agonist, lasI, red fluorescent protein, rsaL.

Quorum sensing (QS) involves the synthesis and exchange of specific signal molecules between cells in a local population of bacteria (Bassler and Losick 2006). When sufficiently high levels of the QS signal accumulate in the cells, changes in gene expression are triggered. This regulatory mechanism enables nearby sibling cells to coordinate behaviors such as motility, mating, stress responses, and biofilm formation. The global importance of QS is indicated by estimates that 5 to $20 \%$ of the genes or proteins in bacteria such as Pseudomonas aeruginosa are directly or indirectly subject to QS regulation (Arevalo-Ferro et al. 2003; Vasil 2003).

Because a variety of important bacterial pathogens depend on QS regulation to induce gene expression related to virulence, tolerance of antibiotics, and biofilm formation, there has been growing interest in finding ways to disrupt bacterial QS (Dong and Zhang 2005; Persson et al. 2005; Rasmussen and Givskov 2006; Riedel et al. 2006). Algae, fungi, and higher

Corresponding author: Wolfgang D. Bauer; E-mail: bauer.7@osu.edu plants have been found to synthesize compounds that can disrupt QS regulation in bacteria by interfering with signal perception. The best-studied example of interference with QS perception involves the halogenated furanones of a marine red alga, Delisea pulchra. The furanones were recognized as being structurally similar to the $N$-acyl homoserine lactone (AHL) QS signals used by various gram-negative bacteria and they were shown to be generally effective inhibitors of QS in such bacteria (Givskov et al. 1996). The Delisea furanones and synthetic analogs appear to act by binding to the LuxR-like protein receptors for AHL QS signals in gram-negative bacteria, enhancing the rate of proteolytic degradation of those receptors and, thus, effectively removing the receptors from a role in QS regulation (Koch et al. 2005; Manefield et al. 2002).

Considerably less is known about the QS-active compounds produced by other eukaryotes. Roots and leaves of various higher plant species secrete QS-active compounds capable of stimulating or inhibiting AHL receptor-mediated gene expression in bacterial reporter strains that synthesize no AHL signals of their own (Degrassi et al. 2007; Gao et al. 2003, 2007; Karamanoli and Lindow 2006; Teplitski et al. 2000). None of these compounds have been chemically identified. However, most of the active compounds in root exudates partition differently in organic solvents than bacterial AHLs, and most of them stimulated QS-regulated gene expression (agonists) rather than inhibiting such expression (antagonists). Thus, these plant compounds appear to be different from both bacterial AHLs and the Delisea furanones. Compounds that inhibit QS responses mediated specifically by the LuxR AHL receptor have also been detected in plant extracts (Persson et al. 2005), especially garlic (Bjarnsholt et al. 2005).

In order to determine the chemical nature of a QS agonist produced by a eukaryote, we fractionated culture filtrate extracts from the unicellular green alga Chlamydomonas reinhardtii and purified various substances that stimulated gene expression mediated by specific AHL receptor proteins.

\section{RESULTS}

Compound purification and identification.

Culture filtrate extracts from Chlamydomonas reinhardtii were purified by high-performance liquid chromatography (HPLC) and assayed for QS-active compounds as described below. Bioassay of fractions from the initial HPLC purification revealed the presence of several chromatographically separable substances that specifically stimulated bacterial reporters based on the LasR, AhyR, or CepR AHL receptors (Steidle et 
al. 2001; Winson et al. 1998). These results are consistent with the previous study of QS-active compounds produced by Chlamydomonas reinhardtii (Teplitski et al. 2004). No LuxR agonists were detected. Except for the LasR agonist activity eluting between 16 and $22 \mathrm{~min}$ in the initial fractionation and 13 and 16 min in the second fractionation, attempts to identify other QSactive substances were unsuccessful.

Material from the peak of LasR agonist activity eluting in methanol at $39 \mathrm{~min}$ in the final purification step was pale, metallic yellow in solution and in dry samples. This material was poorly soluble in water, acetonitrile, and methanol. It appeared to be increasingly solubilized during elution in the final acetonitrile gradient between 31 and $49 \mathrm{~min}$. Mass spectrometry (MS) analyses of this material showed an apparent molecular ion (M-H) of $m / z, 241.6$, which fragmented in MS/MS experiments to produce a secondary ion of $\mathrm{m} / \mathrm{z}$ 198.1. Proton nuclear magnetic resonance (NMR) measurements recorded clear, readily quantified singlet peaks $\left(\delta_{\mathrm{H}}, \mathrm{ppm}\right)$ at $7.94(1 \mathrm{H}), 7.75$ $(1 \mathrm{H}), 2.54(3 \mathrm{H})$, and $2.52(3 \mathrm{H})$. UV-visible spectra in acetonitrile showed peaks at 220,247, 258, 332, and $380 \mathrm{~nm}$. These results are identical to or consistent with those reported previously by this lab (Phillips et al. 1999) and others (Brown et al. 1972; Glebova et al. 1977) for the compound lumichrome, and are consistent with data from parallel measurements here using authentic lumichrome. The structures of lumichrome and its parent, the vitamin riboflavin, are illustrated in Figure 1A.

LasR is stimulated by authentic lumichrome and riboflavin.

Escherichia coli JM109 pSB1075 lasR, $\mathrm{P}_{\text {las I }}$-luxCDABE AHL reporter (Winson et al. 1998) responded reproducibly to dried samples of authentic riboflavin and lumichrome (Fig. 1B), confirming the identification of lumichrome as an LasR agonist and establishing that riboflavin is a comparably effective agonist. Maximal luminescence responses of the reporter to exogenous riboflavin and lumichrome were approximately 15 to $40 \%$ of the maximal responses obtained with $\mathrm{N}$-3-oxo-dodecanoyl homoserine lactone (3-oxo- $\mathrm{C}_{12}$-HSL), the cognate AHL for LasR. When the parallel E. coli reporters, pSB401 (LuxR) and pSB536 (AhyR), were tested under the same conditions, neither reporter was activated appreciably by riboflavin or lumichrome (data not shown). Thus, the stimulation of luxCDABE expression by riboflavin and lumichrome appeared to be specific for the LasR receptor. In these initial assays, methanol suspensions of lumichrome and riboflavin were dried in microtiter plate wells prior to adding the reporter bacteria, similar to the bioassay of dried HPLC fractions from Chlamydomonas reinhardtii The strongest responses to riboflavin and lumichrome were observed when the $E$. coli pSB1075 reporter bacteria were exposed to an amount of the compound that would generate a concentration of $200 \mu \mathrm{M}$ if it all dissolved. However, the maximum solubility of lumichrome in water or culture medium is only approximately $20 \mu \mathrm{M}$, and the particles dissolve slowly. This suggests that perhaps only a small, unknown fraction of the added lumichrome dissolved and was accumulated by the E. coli reporter during the assays.

\section{Responses to riboflavin and lumichrome depend on the AHL-binding domain of LasR.}

To test for possible indirect effects of riboflavin and lumichrome on stimulation of the E. coli pSB1075 lasR, $\mathrm{P}_{\text {lasI }}$ luxCDABE reporter, control constructs were made that lacked the lasR gene or its AHL binding domain but retained either the lasI promoter or the lasR promoter. In the absence of the lasR gene or the AHL-binding domain of LasR (pTIM5319), riboflavin, lumichrome, and 3-oxo- $\mathrm{C}_{12}$-HSL failed to stimulate either the $\mathrm{P}_{\text {las I }}$-luxCDABE or the $\mathrm{P}_{\text {lasR }}$-luxCDABE construct in E. coli JM109 (data not shown). Introduction of a full-length copy of lasR on a low copy number plasmid (pTIM5211) restored responsiveness of the $\mathrm{P}_{\text {las I }}$-luxCDABE construct (pTIM505) to these compounds (data not shown), indicating that luminescence responses to riboflavin and lumichrome in
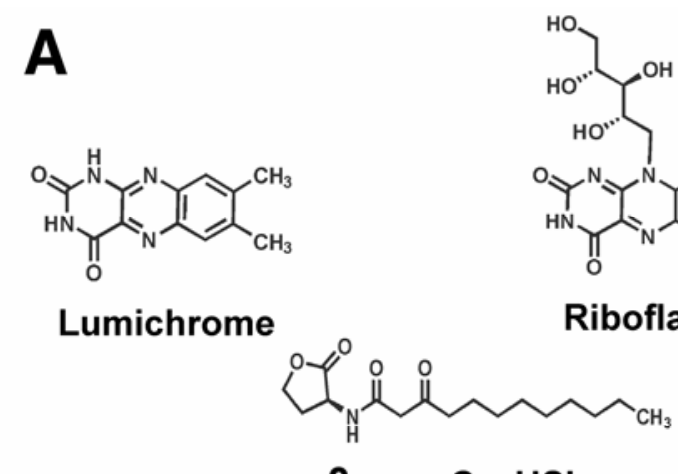

B
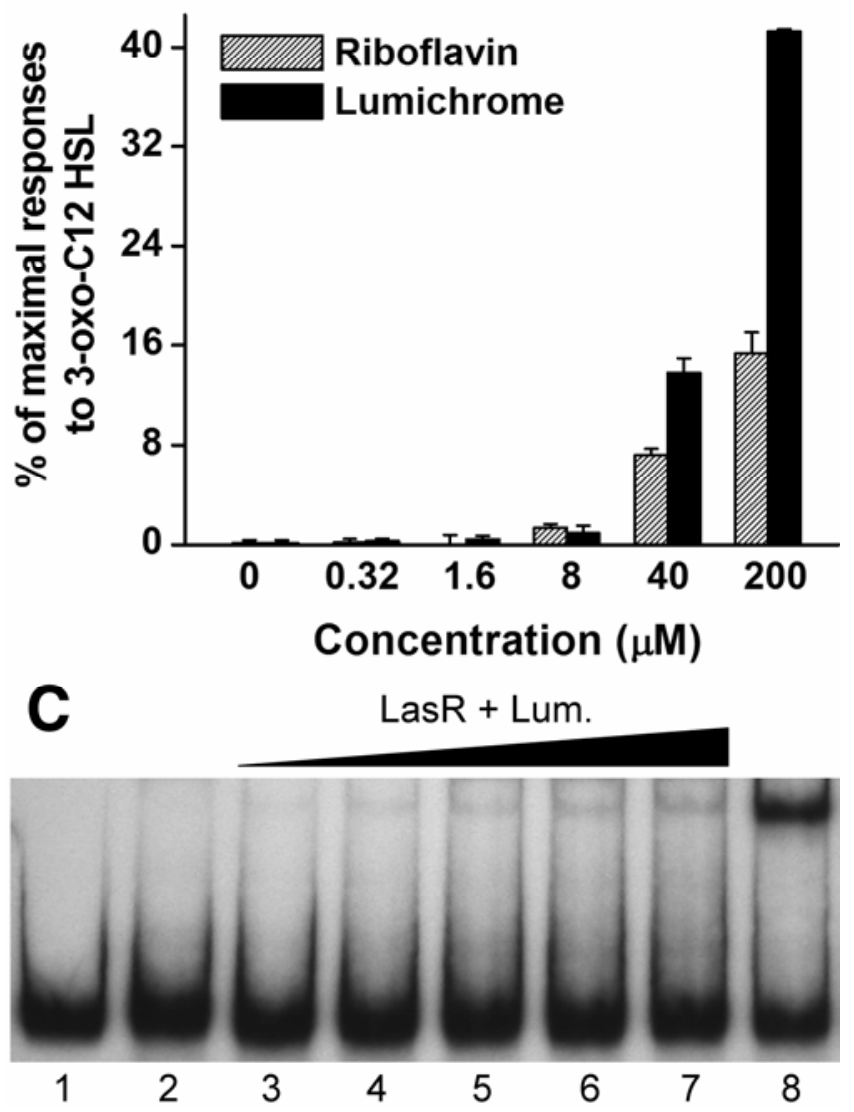

Fig. 1. LasR-dependent responses to lumichrome, riboflavin, and $\mathrm{N}$-3-oxododecanoyl homoserine lactone (3-oxo- $\left.\mathrm{C}_{12}-\mathrm{HSL}\right)$. A, Structures of lumichrome, riboflavin and 3-oxo- $\mathrm{C}_{12}$-HSL. B, Responses of Escherichia coli JM109 pSB1075 to dried samples of the compounds. Aliquots of riboflavin and lumichrome in methanol were dried in microtiter plate wells, mixed with the reporter, and bioassayed. Results are averages ( \pm standard error) from triplicate samples from a representative experiment. C, LasR$\mathrm{P}_{\text {lasI }}$ gel shift. Radiolabeled DNA containing the lasI promoter was incubated with $E$. coli lysates containing LasR which were prepared in the presence of either $20 \mu \mathrm{M}$ lumichrome or $5 \mu \mathrm{M}$ 3-oxo- $\mathrm{C}_{12}-\mathrm{HSL}$, or in the absence of signal. DNA-protein complexes were separated from unbound DNA by electrophoresis and visualized by autoradiography. Radiolabeled DNA was incubated with: lane 1, no lysate; lane 2, lysate containing LasR (10 $\mu \mathrm{g}$ of total protein); lanes 3-7, lysate containing LasR and lumichrome $(4,8,12,16$, and $20 \mu \mathrm{g}$ of total protein, respectively); and lane 8 , lysate containing LasR and 3-oxo- $\mathrm{C}_{12}$-HSL (10 $\mu \mathrm{g}$ of total protein). Results are representative of two independent experiments. 
the reporter were fully dependent on the LasR protein. Thus, it seemed likely that riboflavin and lumichrome, like 3-oxo- $\mathrm{C}_{12^{-}}$ HSL, interact directly with the LasR protein to activate lux gene expression in the reporter. This conclusion was tested further by electrophoretic mobility shift assays.

\section{Lumichrome-activated LasR binds}

to the lasI promoter region.

The ability of exogenously supplied lumichrome to activate the LasR receptor for in vitro binding to the lasI promoter was tested essentially as described by Wade and associates (2005). LasR expressed in $E$. coli DH5 $\alpha$ cells cultured in the presence of $20 \mu \mathrm{M}$ lumichrome induced a shift in a modest fraction of the band of labeled lasI promoter DNA (Fig. 1C), indicating that lumichrome is able to induce LasR to bind PlasI DNA. The intensity of the band was approximately $5 \%$ of that obtained in parallel experiments with comparable amounts of protein isolated from cells exposed to $5 \mu \mathrm{M} 3$-oxo- $\mathrm{C}_{12}$-HSL. The low band intensity may reflect poor entry of lumichrome into DH5 $\alpha$ cells or lower binding affinity.

\section{Riboflavin and lumichrome elicit responses}

in both lasI and $r s a L$ reporter fusions.

The pSB1075 bioluminescence reporter used for the previous bioassays is very sensitive. However, the lasI promoter region that was originally fused to the $\operatorname{luxCDABE}$ genes in this reporter also included the $r s a L$ promoter and the $r s a L$ coding sequence (Winson et al. 1998). In P. aeruginosa, where LasR is normally produced, $r s a L$ and lasI are divergently transcribed from the same intergenic region (de Kievit et al. 1999) (Fig. $2 \mathrm{~A}$ ). Both genes are regulated by LasR, with $r s a L$ normally expressed at higher population densities (3-oxo- $\mathrm{C}_{12}$-HSL concentrations) than lasI. Biologically, the consequences of activating lasI and $r s a L$ are opposite. LasR-mediated induction of lasI expression increases levels of the LasI AHL synthase, leading to enhanced production of 3 -oxo- $\mathrm{C}_{12}$-HSL and amplified expression of the LasR regulon. In contrast, LasR-mediated induction of $r s a L$ leads to synthesis of the RsaL protein which acts as a negative regulator of lasI by binding to the lasI promoter (Rampioni et al. 2006). In assays with the pSB1075 reporter, maximal luminescence responses to 3 -oxo- $\mathrm{C}_{12}$-HSL can be reduced approximately 100 -fold by RsaL-mediated inhibition (data not shown).

Two red fluorescent protein (RFP) reporter plasmids were constructed in order to avoid RsaL-mediated inhibition and to separate the lasI and $r s a L$ promoters from each other. Both the pSRLR (=lasR, $\left.\mathrm{P}_{\text {las }}-r f p\right)$ and pLRTD (=lasR, $\left.\mathrm{P}_{r s a L}-r f p\right)$ reporters showed significantly enhanced accumulation of RFP in response to 3-oxo- $\mathrm{C}_{12}$-HSL, riboflavin, and lumichrome when tested in the E. coli BSV11 ribB mutant (Fig. 2B and C). Responses of these reporters to riboflavin and lumichrome were several times higher in the E. coli BSV11 ribB mutant, a riboflavin auxotroph, than in the JM109 background (data not shown). Based on RFP accumulation, the lasI promoter was induced more strongly by 3 -oxo- $\mathrm{C}_{12}$-HSL than the $r s a L$ promoter and, as expected, it was induced at lower AHL concentrations (Fig. 2B and C). Maximal

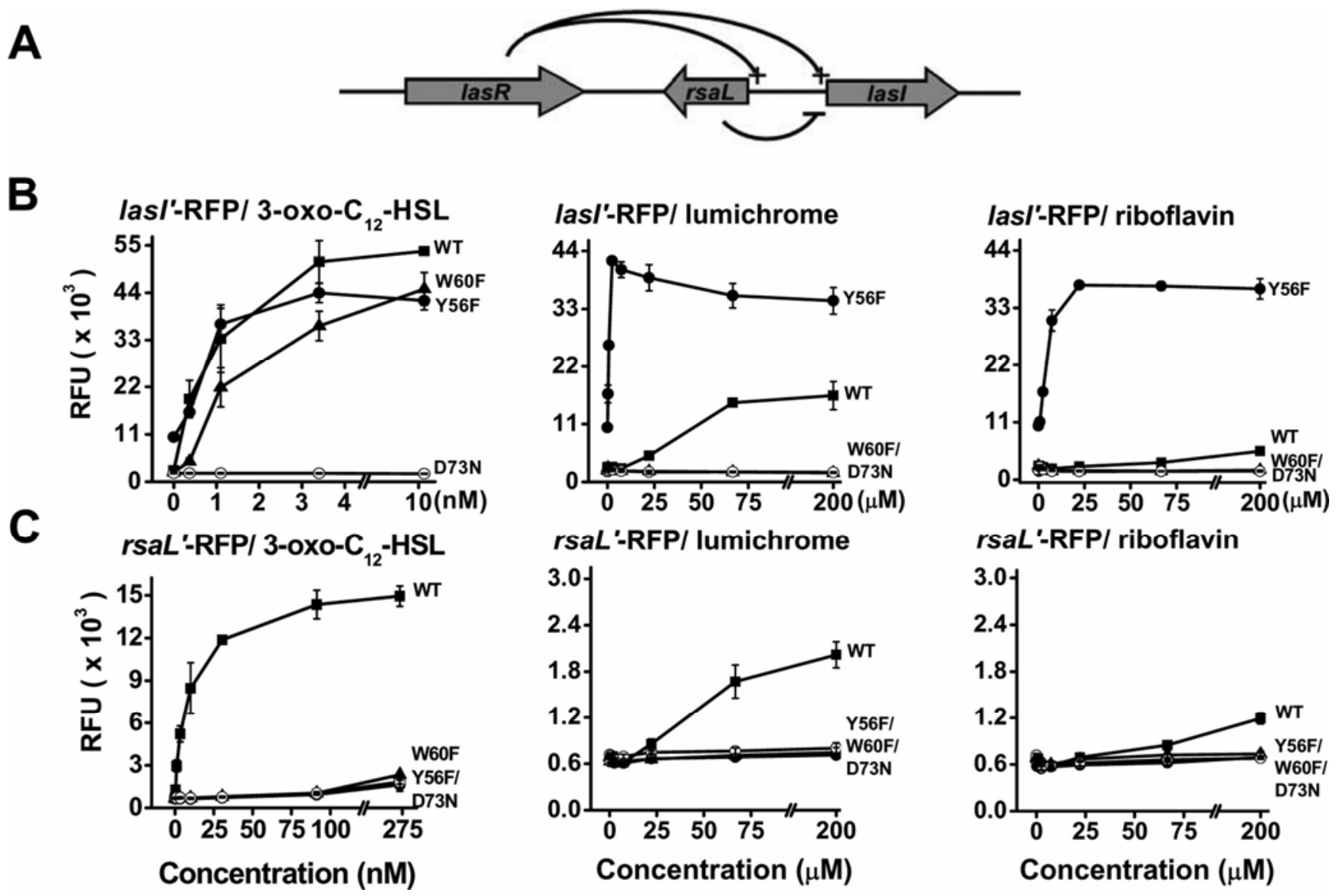

Fig. 2. $\mathrm{P}_{\text {last }}-r f p$ and $\mathrm{P}_{r s a L}-r f p$ reporter responses to $N$-3-oxo-dodecanoyl homoserine lactone (3-oxo-C 12 -HSL), lumichrome, and riboflavin. A, LasR in Pseudomonas aeruginosa activates the lasI and rsaL promoters while RsaL blocks the lasI promoter. Escherichia coli BSV11 ribB::Tn5 strains carrying either $\mathbf{B}, \mathrm{P}_{l a s}-r f p$ reporter plasmids or $\mathbf{C}, \mathrm{P}_{r s a L}-r f p$ reporter plasmids were tested for responses to dried samples of 3-oxo-C ${ }_{12}$-HSL, lumichrome, and riboflavin. Each red fluorescent protein (RFP) reporter plasmid carries a copy of the las $R$ gene encoding either the normal LasR receptor (WT) or a LasR receptor with the D73N, W60F, or Y56F amino acid substitution. Responses in relative fluorescence units (RFU) are averages ( \pm standard error) from triplicate samples for a representative experiment. 
lasI activation by 3 -oxo- $\mathrm{C}_{12}$-HSL was approximately 4 times higher than maximal activation by lumichrome (Fig. 2B), whereas maximal $r s a L$ activation by 3 -oxo- $\mathrm{C}_{12}$-HSL was approximately 7.5 times higher than maximal activation by lumichrome (Fig. 2C). Although these differences are not large, they were consistent and seem potentially interesting.

To test whether or not lumichrome and riboflavin interact with the same part of the AHL-binding domain as 3 -oxo- $\mathrm{C}_{12^{-}}$ HSL, we also constructed RFP reporters parallel to pSRLR and pLRTD that had single amino acid substitutions in residues Y56, W60, and D73 of the LasR receptor protein. These amino acid residues are highly conserved in the LuxR family of AHL receptors. Based on the crystallographic structure of the homologous TraR receptor (Vannini et al. 2002; Zhang et al. 2002) and amino acid substitution studies in LuxR (Koch et al. 2005), amino acid residues Y56, W60, and D73 were likely to be involved in hydrogen bonding of LasR to the 1-carbonyl, the ring carbonyl, and the NH group, respectively, of AHL QS signals. These roles are in agreement with the recent crystallographic structure of LasR bound to 3 -oxo- $\mathrm{C}_{12}$-HSL (Bottomley et al. 2007).

The D73N amino acid substitution in LasR reduced accumulation of RFP in response to both lumichrome and riboflavin to below detectable limits with the pSRLR $\left(\mathrm{P}_{\text {lasI }}\right)$ reporter as well as the pLRTD $\left(\mathrm{P}_{r s a L}\right)$ reporter (Fig. $2 \mathrm{~B}$ and $\mathrm{C}$ ). The $\mathrm{D} 73 \mathrm{~N}$ substitution also greatly reduced maximal responses to 3-oxo- $\mathrm{C}_{12}$-HSL for the $r s a L$ reporter (Fig. 2C) and required 50- to 100-fold higher concentrations of 3-oxo- $\mathrm{C}_{12}$-HSL for maximal activation of the lasI reporter (data not shown). Thus, the aspartate residue at position 73 appears to be crucial to the activation of LasR by 3 -oxo- $\mathrm{C}_{12}$-HSL, riboflavin, and lumichrome for induced expression of both lasI and $r s a L$.

The W60F substitution in LasR modestly affected responses of the $\mathrm{P}_{\text {las I }}-r f p$ reporter to 3-oxo- $\mathrm{C}_{12}$-HSL, shifting them to concentrations roughly threefold higher than for the wild-type LasR receptor (Fig. 2B). However, the W60F substitution greatly reduced responses of the $\mathrm{P}_{r s a L}$ reporter to 3-oxo- $\mathrm{C}_{12^{-}}$ HSL (Fig. 2C). This substitution also reduced the responses of both $\mathrm{P}_{\text {las }}-r f p$ and $\mathrm{P}_{r s a L}-r f p$ reporters to riboflavin or lumichrome to below detectable limits (Fig. 2B and C). Thus, the tryptophan at position 60 appears to be crucial to the activation of LasR by lumichrome and riboflavin, and this residue is either modestly or strongly important to activation of LasR by 3-oxo$\mathrm{C}_{12}$-HSL, depending on the promoter tested.

The Y56F substitution resulted in high background expression of the $\mathrm{P}_{\text {las I }}-r f p$ reporter (Fig. $2 \mathrm{~B}$ ) but not the $\mathrm{P}_{r s a L}$-rfp reporter (Fig. 2C). The Y56F substitution had relatively little effect on responses of the lasI reporter to 3 -oxo- $\mathrm{C}_{12}$-HSL (Fig. 2B). In contrast, it substantially reduced responses of the $r s a L$ reporter to the AHL (Fig. 2C). Thus, as with the W60F substitution, the effects of the Y56F substitution on activation by 3 oxo- $\mathrm{C}_{12}$-HSL depends strongly on the promoter tested. These findings may provide some insight into the evolutionary constraints on LasR structure in relation to the relative activation of specific promoters.

Unexpectedly, the $\mathrm{P}_{\text {lasl }}-r f p$ reporter with the Y56F substitution in LasR responded much more strongly to added riboflavin and lumichrome than the reporter with wild-type LasR (Fig. 2B). For example, exposure to $2.5 \mu \mathrm{M}$ lumichrome induced the $\mathrm{Y} 56 \mathrm{~F}$ LasR $\mathrm{P}_{\text {las }}-r f p$ reporter to maximum levels whereas the wild-type LasR reporter was not detectably stimulated by this concentration of exogenous lumichrome (Fig. 2B). It appears that the Y56F substitution may selectively enhance lumichrome or riboflavin binding or activation of the receptor for lasI expression without greatly affecting lasI induction by 3-oxo- $\mathrm{C}_{12}$-HSL. In contrast, the Y56F substitution substantially reduced the ability of 3 -oxo- $\mathrm{C}_{12}$-HSL as well as ribo- flavin and lumichrome to stimulate expression of the $\mathrm{P}_{r s a L}$ reporter (Fig. 2C). These opposing effects of the Y56F substitution on lumichrome or riboflavin activation of the two promoters cannot be explained by substitution-altered stability of the LasR protein, nor can altered protein stability explain the promoter-dependent effects of the W60F substitution. The analogous D73N substitution in LuxR abolished responses to its cognate AHL without significantly affecting the stability of the LuxR protein (Koch et al. 2005).

\section{In silico modeling}

of riboflavin or lumichrome interactions with LasR.

Computer docking analyses indicate that both riboflavin and lumichrome occupy the same binding pocket of LasR as 3oxo- $\mathrm{C}_{12}$-HSL (Fig. 3), consistent with their identification as LasR agonists based on bioassays and amino acid substitution studies. The docking space occupied by 3 -oxo- $\mathrm{C}_{12}$-HSL overlaps the spaces where lumichrome and riboflavin appear to bind; however, lumichrome docked in a different space than riboflavin, perhaps due to steric hindrance of the ribityl group. A synthetic triphenyl compound was recently found to activate expression of an rsaL-yfp fusion and to dock with LasR in essentially the same binding pocket as the AHL (Muh et al. 2006 b), in agreement with the notion that LasR is able to recognize both AHLs and structurally dissimilar compounds.

\section{DISCUSSION}

The Delisea furanones were the first eukaryotic antagonists of bacterial QS to be chemically identified. Lumichrome appears to be the first metabolite from a eukaryote identified as a bacterial QS agonist. Although antagonists of QS have been the primary focus of recent studies, compounds that stimulate QS merit interest for several reasons. Chemically, as exemplified by lumichrome, agonists may include new classes of QS-active com-

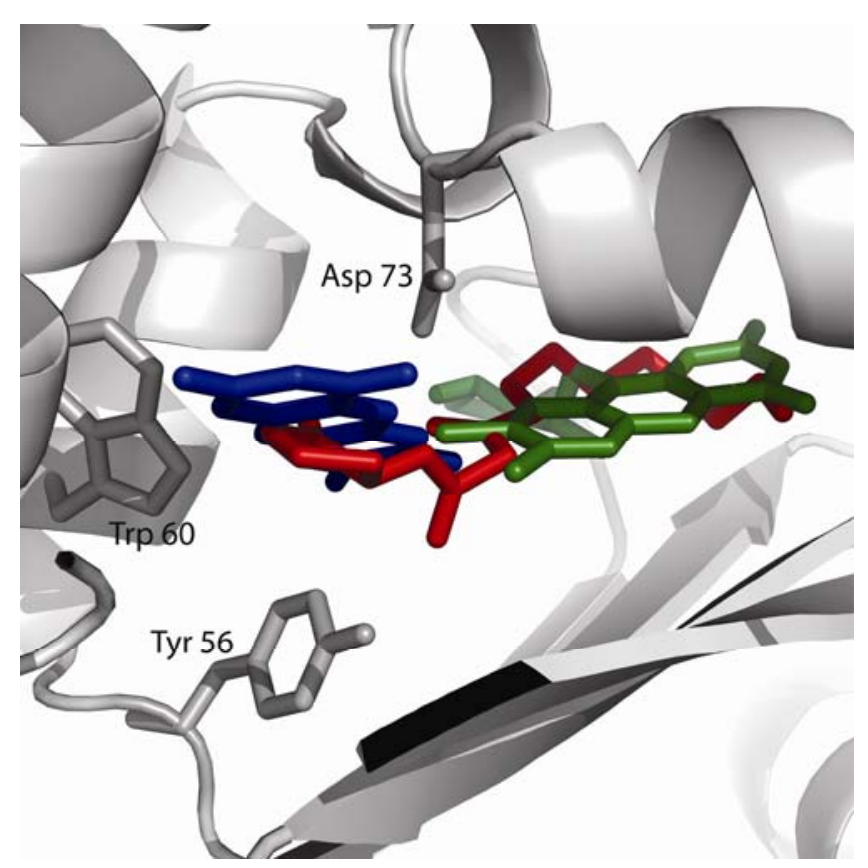

Fig. 3. Docking of $\mathrm{N}$-3-oxo-dodecanoyl homoserine lactone (3-oxo- $\mathrm{C}_{12}{ }^{-}$ HSL), lumichrome, and riboflavin in the $N$-acyl homoserine lactone (AHL) binding pocket of LasR. The locations of docked ligands and amino acids D73, W60, and Y56 are shown in a ribbon illustration of the AHL binding pocket region of the LasR protein. Lumichrome (blue) and riboflavin (green) were docked with LasR independently but are shown superimposed with the location of 3-oxo-C $\mathrm{C}_{12}$-HSL (red) as determined from the crystal structure of LasR (Bottomley et al. 2007). 
pounds, distinct from known QS signals or antagonists. Biologically, agonists produced by host organisms may prove to be as important as antagonists in manipulating bacterial QS regulation. For example, QS agonists from a host might serve to initiate specific, mutually beneficial changes in QS-regulated gene expression in symbiotic bacteria. QS agonists could also protect host organisms from pathogens by prematurely inducing QSregulated virulence gene expression in prequorate populations, leading to activation of host defenses before the pathogens are able to infect or damage the host. QS agonists could also have diverse and unexpected effects on QS regulation in host-associated bacteria beyond the simple stimulatory effects suggested by assays with a specific reporter. For example, another purified LasR agonist from Chlamydomonas reinhardtii affected QS in wild-type Sinorhizobium meliloti not only as an agonist but also as an antagonist, synergist, and canceller of different AHL-inducible changes in protein accumulation (Teplitski et al. 2004).

The halogenated furanones previously identified as antagonists of AHL-mediated QS are structurally rather similar to AHLs (Givskov et al. 1996). Thus, it is not surprising that both the furanones and AHLs interact directly with AHL receptor proteins (Koch et al. 2005). Lumichrome, however, has very little structural similarity to AHLs (Fig. 1A). Therefore, its identification as a compound capable of stimulating the LasR AHL receptor was quite unexpected. The possibility that AHL receptors might recognize more than one kind of compound was suggested earlier (Holden et al. 1999) based on AHL receptor-mediated responses in bacteria to cyclic dipeptides. The effects of cyclic dipeptides on QS regulation were originally regarded as fortuitous "cross-talk" because millimolar cyclic dipeptide concentrations were required to elicit responses. The discovery that lumichrome or riboflavin can activate specific AHL receptors suggests the need to reexamine cyclic dipeptides as potential in vivo QS signals or mimics.

It is not clear whether the LasR receptor of $P$. aeruginosa is unique in its ability to be activated by lumichrome and riboflavin. P. putida, a common rhizosphere inhabitant, for example, has a QS AHL synthase, receptor, and regulator very similar to LasI, LasR, and Rsal in P. aeruginosa (Bertani et al. 2007), and this QS system plays an important role in regulating biofilms (Arevalo-Ferro et al. 2005). Lumichrome and riboflavin did not act as agonists of the LuxR or AhyR reporters. Receptors such as LuxR and AhyR may prove to recognize other classes of bacterial metabolites in addition to AHLs. For example, recent studies indicate that SdiA, the AHL receptor of E. coli (Ahmer 2004), might interact with the common metabolite indole as well as AHLs to regulate biofilm formation (Lee et al. 2007).

The identification of a vitamin and a vitamin derivative as QS-active compounds is new and unexpected. It raises interest in learning more about the factors that control the synthesis, secretion, and uptake of riboflavin, lumichrome, and perhaps other vitamins in bacteria. It also raises the question of whether riboflavin and lumichrome might serve as QS signals in bacteria, perhaps ancestral to other QS signals. Many bacteria are known to secrete riboflavin or lumichrome (Bacher et al. 2000; Phillips et al. 2000). In view of such possibilities, it is important to recognize that our present work provides no direct evidence that riboflavin or lumichrome actually serve as natural QS signals, mimics, or regulators in bacteria. Future studies to explore these possibilities face some important technical limitations. Unlike AHLs, riboflavin and lumichrome do not appear to exchange freely across bacteria cell membranes. No transport systems have yet been identified in any bacterium possessing AHL receptors that might serve to facilitate riboflavin or lumichrome uptake. Nor has the gene encoding a lumichrome synthase been identified in any organism, even though older reports describe the isolation and partial characterization of lumichrome synthases (riboflavin hydrolases) from both plants and bacteria (Foster and Yanagita 1956; Kumar and Vaidyanathan 1964; Yang and McCormick 1967). Nor can the synthesis of riboflavin be manipulated without risking significant effects on metabolic functions other than QS. At present, these factors make it difficult to rigorously analyze QS-related responses to either endogenous or exogenous riboflavin or lumichrome. In P. aeruginosa, for example, the addition of $10 \mu \mathrm{M}$ lumichrome stimulated a $\mathrm{P}_{\text {lasl-rfp }}$ reporter twofold over background, comparable with maximal three- to fourfold stimulation of the promoter by 3-oxo- $\mathrm{C}_{12}$-HSL; however, this stimulation was seen only when the promoter was mutated to reduce RsaL binding and when lasR was provided on a multicopy plasmid (data not shown). Thus, the observed responses do not establish whether lumichrome plays a significant role in normal P. aeruginosa QS.

Lumichrome and riboflavin have signal-level effects in various organisms that are independent of QS, effects that help provide a context for understanding their potential QS-related roles. In earlier studies, lumichrome was purified and identified from culture filtrates of $S$. meliloti as a compound responsible for stimulating root respiration and plant growth in its symbiotic partner, alfalfa (Phillips et al. 1999). Subsequent studies have shown that exposure to $5 \mathrm{nM}$ lumichrome significantly stimulates seedling development in both legume and cereal crops (Matiru and Dakora 2005a,b), and triggers diverse changes in gene expression in Arabidopsis (T. Fox, W. Bauer, and D. Phillips, unpublished). Application of $10 \mathrm{nM}$ lumichrome to roots also reduced stomatal conductance in bean (Joseph and Phillips 2003) whereas application of micromolar lumichrome enhanced photosynthesis in corn and soybean (Khan et al. in press). These responses suggest that lumichrome has important regulatory roles in plants. Lumichrome was also identified as an inducer of ascidian larval settlement and metamorphosis (Tsukamoto et al. 1999), indicating that it may serve as a developmental signal in animals as well as plants. In plants, there are also hints that riboflavin, or the riboflavin synthesis pathway, has roles in plant signal transduction. Foliar application of riboflavin elicited systemic pathogen resistance in both tobacco and Arabidopsis via specific signaling pathways (Dong and Beer 2000). Disruption of a gene encoding the enzyme required for synthesis of lumazine, the precursor of riboflavin, affected jasmonate-mediated signaling in Arabidopsis, including defense responses (Xiao et al. 2004).

These responses of eukaryotes to exogenous riboflavin and lumichrome suggest that diverse bacteria could benefit by secreting the compounds during host interactions. In turn, plants, fungi, and algae could perhaps benefit by secretion of riboflavin or lumichrome to manipulate QS in those bacteria with LasR-like receptors.

\section{MATERIALS AND METHODS}

\section{Collection, purification, and bioassay}

of QS-active compounds from Chlamydomonas reinhardtii.

Chlamydomonas reinhardtii CC-2137, initially isolated from soil, was grown in the light on acetate-containing TAP mineral medium (Harris 1989). Culture filtrates were obtained by centrifugation and passage through glass fiber filters and then subjected to solid phase extraction in 20-liter batches passed through $10-\mathrm{g} \mathrm{C}_{18}$ columns (Megabond Elute, Varian, Sunnyvale, CA, U.S.A.) in reverse-phase mode. After rinsing with water, the columns were eluted first with $35 \mathrm{ml}$ of methanol and then with $35 \mathrm{ml}$ of acetonitrile. The two solvent eluates were dried under nitrogen and stored at $-20^{\circ} \mathrm{C}$. The compounds were solubilized in 1:1 acetonitrile/water and fractionated in three initial stages on a Waters HPLC employing a model 996 photodiode array detector and two model 510 pumps controlled by Millennium soft- 
ware. Stage I involved injecting 10-liter culture equivalents in 10 individual cycles on a semipreparative HPLC column (Alltech Hypersil $\mathrm{C}_{18}, 199$ by $10 \mathrm{~mm}$ ), which had been equilibrated in acetonitrile/water (1:9). This column was eluted at $2 \mathrm{ml} / \mathrm{min}$ with acetonitrile/water (1:9) for $5 \mathrm{~min}$, followed by a gradient of 10 to $100 \%$ acetonitrile from 5 to $25 \mathrm{~min}$, and then with $100 \%$ acetonitrile from 25 to $50 \mathrm{~min}$. Aliquots of the HPLC fractions were bioassayed with the E. coli pSB1075 (LasR), pSB401 (LuxR), and pSB536 (AhyR) (Winson et al. 1998) and P. putida CepR (Steidle et al. 2001) AHL reporter strains as previously described (Gao et al. 2005; Teplitski et al. 2004), testing for either direct activation of the reporters by compounds from the alga or for inhibition of reporter responses to added AHLs by algal substances. Reporter luminescence or green fluorescent protein fluorescence were measured with a microtiter plate reader at 37 or $30^{\circ} \mathrm{C}$ for E. coli and P. putida reporters, respectively, 3 to $8 \mathrm{~h}$ after addition of the reporter suspension to aliquots of the HPLC fractions dried under vacuum in the wells. Aliquots of active fractions were retested to confirm activity and only those activities at least threefold above reporter-only controls were considered significant. No compounds with significant agonist or antagonist activities were detected with any of the AHL reporters in fractions from the acetonitrile washes of the solid-phase extraction columns, indicating that the initial elution with methanol eluted essentially all of the absorbed QSactive compounds detectable with these reporters.

Further purification of QS-active algal substances focused on one compound capable of stimulating the pSB1075 reporter that eluted between 16 and 22 min during stage I purification. Pooled active fractions 16 to 22 obtained from nine additional runs equivalent to the first were freeze dried. In stage 2 , the freeze-dried material from stage 1 was solubilized in acetonitrile/water (1:1) and applied in four separate runs to the same column equilibrated in acetonitrile/water (1:9). This was eluted at $2 \mathrm{ml} / \mathrm{min}$ using acetonitrile/water (1:9) for 0 to $5 \mathrm{~min}$, followed by a gradient of 10 to $30 \%$ acetonitrile for 5 to $85 \mathrm{~min}$ and 30 to $60 \%$ acetonitrile for 85 to $100 \mathrm{~min}$. The LasR stimulatory activity eluted between 13 and 16 min under these conditions. Samples from the four duplicate runs were combined and lyophilized. In stage 3 , the active material was solubilized in acetonitrile/water (1:3) and fractionated on the same column equilibrated with acetonitrile/water (1:9) and eluted at 2 $\mathrm{ml} / \mathrm{min}$ using acetonitrile/water (1:9) for 0 to $5 \mathrm{~min}$, followed by a gradient of 10 to $40 \%$ acetonitrile for 5 to $85 \mathrm{~min}$ and $100 \%$ acetonitrile for 85 to $100 \mathrm{~min}$. Large amounts of diverse compounds were still evident by UV absorbance across most of elution profile in this separation; however, a clear peak of absorbance and LasR stimulatory activity was present at 48 to $49 \mathrm{~min}$. Material present in this peak was lyophilized and rerun under the same conditions, producing a broad peak of material that was spectrally uniform in the range of 200 to 400 $\mathrm{nm}$ and had LasR stimulatory activity proportional to the absorbance. This broad peak of activity started to elute at 31 min and reached a maximum at $49 \mathrm{~min}$. Final HPLC purification was achieved by pooling the active fractions, drying them, dissolving them in 1:1 methanol/water, and running them on an analytical column equilibrated in methanol/water (1:9) and eluted at $1 \mathrm{ml} / \mathrm{min}$ with a gradient of 10 to $100 \%$ methanol from 5 to $55 \mathrm{~min}$. Under these conditions a sharp, symmetrical, spectrally uniform ( 240 to $400 \mathrm{~nm}$ ) peak with LasR stimulatory activity eluted with maximum absorbance and activity at 39.7 min. Material in this peak was used for UV-visible, mass spectrometric, and NMR analyses. MS data were obtained at the University of California-Davis (UCD) Advanced Instrumentation Facility on a Finnegan LC-ion-trap MS, model LC$\mathrm{Q}$, using negative mode electro spray ionization after injecting samples in methanol/water (1:1). Tandem MS-MS or MS-MS-
MS experiments were conducted by increasing the translational energy of the selected ion and then detecting the major daughter ions. Proton nuclear magnetic resonance $\left({ }^{1} \mathrm{H}-\mathrm{NMR}\right)$ analyses were conducted at the UCD NMR Facility with a $600-\mathrm{MHz}$ Broker Advance DRX-600 operating on XWINNMR software 2.1. Tetramethylsilane was added as an internal standard to the deuterated methanol solvent.

\section{Bioassay of responses to riboflavin and lumichrome.}

E. coli strains carrying AHL reporter plasmids were taken from glycerol stocks and shake cultured at $37^{\circ} \mathrm{C}$ overnight in M9 medium (Meade and Signer 1977) containing 1\% tryptone and the appropriate antibiotic. The cultures were diluted 20fold into fresh medium, subcultured for 1 to $2 \mathrm{~h}$, then diluted 10 -fold into fresh medium. Triplicate $100-\mu \mathrm{l}$ portions were dispensed into black microtiter plate wells containing dried samples of 3-oxo- $\mathrm{C}_{12}-\mathrm{HSL}$, riboflavin, or lumichrome from methanol solutions or suspensions. Plates were incubated at $37^{\circ} \mathrm{C}$ and luminescence was measured 4 to $8 \mathrm{~h}$ later for $l u x$ reporters. For RFP reporters, fluorescence was measured 16 to $48 \mathrm{~h}$ after adding a twofold diluted, 1-h subculture to the microtiter plates. For RFP reporters, fluorFluorescence was measured after 16 to $48 \mathrm{~h}$ for RFP reporters. The $E$. coli BSV11 ribB::Tn5 mutant was obtained from the E. coli Genetic Stock Center, Yale University. Bioassays with reporter plasmids in this mutant were conducted with $500 \mathrm{nM}$ riboflavin in the medium.

\section{Construction of las control plasmids.}

Primers used to construct the $\mathrm{P}_{\text {las I }}$-luxCDABE and $\mathrm{P}_{\text {lasR }}{ }^{-}$ luxCDABE control reporters pTIM505, pTIM84, and pTIM5319 are listed in Table 1. pTIM84, a $\mathrm{P}_{\text {lasR }}$-luxCDABE reporter, was constructed by amplifying the las $R$ promoter with BA1404 and BA1415 using pSB1075 as a template. The product was then cloned upstream of the promoterless luxCDABE cassette in pSB377 (Winson et al. 1998). pTIM505 consists of just the lasI' promoter amplified from pSB1075 with BA1403 and BA439 and cloned upstream of the luxCDABE cassette. To confirm that the lasI promoter cloned in pTIM505 was functional, the full-length lasR was supplied in trans on pTIM5211. The resulting reporter JM109 pTIM505 pTIM5211 was fully responsive to 3-oxo-C ${ }_{12}$-HSL. pTIM5211 was constructed by Pfu polymerase-catalyzed polymerase chain reaction (PCR) amplification of the full-length las $R$ with its own promoter using BA1404 and BA1407. The resulting fragment was cloned into pWSK129. The pTIM5319 control plasmid is a chimeric construct identical to pSB1075 but lacks sequences for the AHL-binding domain of LasR. To construct pTIM5319, the las $R$ promoter and the codons corresponding to the first five amino acids of the protein were PCR amplified with BA1404 and BA1415; the remainder of the gene and the downstream lasI promoter were amplified with BA1403 and BA439 using pSB1075 as template. The resulting 387- and 676-bp products were gel purified and in vitro phosphorylated with T4 PNK polynucleotide kinase, and the reaction products were then purified, ethanol precipitated, and ligated overnight with T4 HC ligase. The ligation reaction was used as a template for a Pfu-catalyzed PCR amplification using primers BA1404 and BA439. The resulting 1,053-bp fragment was gelpurified and cloned into pCR-Blunt II-TOPO, from which it was excised with EcoRI and gel-purified and ligated into EcoRI, calf intestinal alkaline phosphatase-treated pSB377. The resulting constructs were confirmed by sequencing.

\section{Construction of RFP reporter plasmids and LasR amino acid substitution mutants.}

The $\mathrm{P}_{l a s}-r f p$ and $\mathrm{P}_{r s a L}-r f p$ plasmids pSRLR and pLRTD were constructed as derivatives of the rasL-yfp plasmid pUM15 
(Muh et al. 2006a). The synthetic RFP-designated tdTomato (Shaner et al. 2004) was used to replace yellow fluorescent protein (YFP) in pUM15 in order to avoid the strong fluorescence of riboflavin and lumichrome. The tdTomato gene was amplified using primers 5'RFP and 3'RFP (Table 1) using pCR2.1v-tdTomato (Shaner et al. 2004) as template. The PCR product was digested with HindIII and $\mathrm{XbaI}$ and then cloned into pUC19. The resulting plasmid was digested with HindIII/ ScaI and used to replace YFP in pUM15, thus creating the $r s a L^{\prime}$-tdTomato reporter designated pTD. To create the pLRTD (lasR, $\mathrm{P}_{r s a L}$-tdTomato) reporter plasmid, the lasR gene was amplified from template pSB1075 (Winson et al. 1998) with 5'LasR and 3'LasR-1. The lasR PCR product and vector pTD were digested with $K p n I$ and AatII and ligated to create pLRTD. The $\mathrm{P}_{\text {las }}-r f p$ reporter plasmid $\mathrm{pSR}$ and the lasR, $\mathrm{P}_{\text {lasl }}{ }^{-}$ $r f p$ reporter plasmid pSRLR were created by first cloning the lasI promoter $\left(\mathrm{P}_{\text {lasI }}\right)$ into the broad-host-range plasmid pBBR1MCS5 (Kovach et al. 1995). $\mathrm{P}_{\text {las I }}$ was PCR amplified with 5'PrLasI and 3'PrLasI using pSB1075 as a template. The PCR product was digested with Bam $\mathrm{HI}$ and HindIII and cloned into pBBR1MCS5, making pBBR1MCS5-P $\mathrm{P}_{\text {las }}$. To create a $\mathrm{P}_{\text {las }} I^{-}$ tdTomato fusion, the tdTomato-lasR cassette in pLRTD was PCR amplified with 5'RFP and 3'LasR-2, then digested with HindIII and ApaI and cloned downstream of $\mathrm{P}_{\text {lasI }}$ in pBBR1MCS5- $\mathrm{P}_{\text {las }}$, creating $\mathrm{pBRC12}$. The $\mathrm{pBRC12}$ construct was digested with Bam $\mathrm{HI}$ to release the $\mathrm{P}_{\text {lasI }}$-tdTomato cassette, which was then used to replace the $\mathrm{P}_{r s a L}$-tdTomato cassette in the pTD and pLRTD plasmids. All constructs were confirmed by sequencing. Site-directed mutations in las $R$ were created using the plasmids pSRLR and pLRTD as templates using the QuikChange XL site-directed mutagenesis kit (Stratagene, La Jolla, CA, U.S.A.) as detailed in the user's manual. The substitution mutants were confirmed by sequencing.

\section{Electrophoretic mobility shift assays.}

Experiments were conducted essentially as described (Wade et al. 2005) with LasR overproduced in E. coli cultures exposed to either $5 \mu \mathrm{M}$ 3-oxo- $\mathrm{C}_{12}$-HSL or $20 \mu \mathrm{M}$ lumichrome. Overnight cultures of $E$. coli $\mathrm{DH} 5 \alpha$ carrying either plasmid pECP8 $\left(\mathrm{P}_{\text {tac }}{ }^{-}\right.$ lasR) or vector plasmid pEX1.8 (Pearson et al. 1997) were subcultured to an optical density of 0.05 at $600 \mathrm{~nm}$ into LuriaBertani medium buffered with $50 \mathrm{mM}$ MOPS and supplemented with either $5 \mu \mathrm{M}$ 3-oxo- $\mathrm{C}_{12}$-HSL or $20 \mu \mathrm{M}$ lumichrome. Subcultures were grown at $37^{\circ} \mathrm{C}$ with shaking for $3 \mathrm{~h}$, and then isopropyl- $\beta$-D-thiogalactoside was added to a final concentration of $1 \mathrm{mM}$ to induce expression of LasR. Cultures were then incubated another $2 \mathrm{~h}$, after which the cells were harvested by centrifugation. Lysates were prepared by passing the cells through a French pressure cell at 16,000 psi. The total protein concentration of lysates was determined using the Bradford protein assay (Bio-Rad, Hercules, CA, U.S.A.). A 241-bp DNA fragment containing the lasI promoter region was amplified by PCR using primers 5'-TTTTGGGGCTGTGTTCTC TC-3' and 5'-CACTTGAGCACGCAACTTGT-3', and $P$. aeruginosa PAO1 chromosomal DNA as template. DNA fragments were radiolabeled with $\left[\gamma_{-}{ }^{32} \mathrm{P}\right]$ ATP (Perkin-Elmer, Norwalk, CT, U.S.A.) by using T4 polynucleotide kinase (Invitrogen, Carlsbad, CA, U.S.A.). DNA-binding reactions were carried out in the buffer described by Wade and associates (Wade et al. 2005). Each binding reaction contained radiolabeled DNA equivalent to approximately $6 \times 10^{4}$ counts per minute, $0.5 \mu \mathrm{g}$ of salmon sperm DNA, and lysate containing 0 to $20 \mu \mathrm{g}$ of protein. Reactions were incubated at room temperature for 20 min and then separated on a native $6 \%$ polyacrylamide gel. Radiolabeled fragments were visualized by autoradiography after 2 days of exposure of X-ray film. All binding reactions containing $E$. coli lysate, both with and without LasR present and regardless of the presence or absence of signal, caused a shift in the mobility of the radiolabeled lasI promoter fragment (data not shown). The mobility shift created by LasR in combination with either lumichrome or 3 -oxo- $\mathrm{C}_{12}$-HSL was clearly distinct from the shift caused by $E$. coli lysate alone.

\section{Lumichrome and riboflavin docking.}

The X-ray crystal structure coordinates of the LasR protein and ligands were obtained from the protein data bank: LasR, Protein Data Bank (pdb) identification number 2UV0; 3-oxo$\mathrm{C}_{12}$-HSL, pdb identification number 2UV0; lumichrome, pdb identification number 2CC7; and riboflavin, pdb identification number 1BU5. Dockings of lumichrome and riboflavin with

Table 1. Primers

\begin{tabular}{|c|c|c|c|}
\hline Primer & Sequence & Description & Reference \\
\hline BA439 & CACTAACGTCCCAGCCTTTGCGCTC & Binds at nt 1559362 of PAO1 genome AE004091 within lasI & Winson et al. 1998 \\
\hline BA1403 & TTCTCTCGTGTGAAGCCATTGCTCTGAT & $\begin{array}{l}\text { Binds at nt } 1559104 \text { of AE004091 upstream of the lasI } \\
\text { promoter }\end{array}$ & This study \\
\hline BA1404 & GCGTGGCGATGGGCCGACAGTG & $\begin{array}{l}\text { Binds at nt } 1557820 \text { of AE004091, upstream of the lasR } \\
\text { promoter }\end{array}$ & Winson et al. 1998 \\
\hline BA1407 & ACCTGAGAGGCAAGATCAGAGAGTAAT & Binds at nt 1558905 , downstream from lasR & This study \\
\hline BA1415 & GCGTTCCAGCTCAAGAAAACCGTC & Binds at nt 1558206 of AE004061 within lasR & This study \\
\hline 5'RFP & $\begin{array}{l}\text { ACAAGCTTAGCTAAGGAGATCTAAATATGGTG } \\
\text { AGCAAGGGCGAGGA }\end{array}$ & $\begin{array}{l}5^{\prime} \text { tdRFP primer with in-frame three translational stops, } \\
\text { T7gene10 SD and HindIII }\end{array}$ & This study \\
\hline 3'RFP & TCTAGATTACTTGTACAGCTCGTCCATGCCGTA & $3^{\prime}$ tdRFP primer with in-frame translational stop and $\mathrm{XbaI}$ & This study \\
\hline 5'LasR & CAGGTACCGCGTGGCGATGGGCCGAC & $5^{\prime}$ LasR primer with KpnI, binds at nt 1557817 of AE004091 & This study \\
\hline 3'LasR-1 & $\begin{array}{l}\text { CGGACGTCTCAGAGAGTAATAAGACCCAAAT } \\
\text { TAACGGCCATAATG }\end{array}$ & 3' LasR primer with AatII binds at nt 1558893 of AE004091 & This study \\
\hline 3'LasR-2 & $\begin{array}{l}\text { CGGGGCCCTCAGAGAGTAATAAGACCCAAAT } \\
\text { TAACGGCCATAATG }\end{array}$ & Similar to 3'LasR-1 with AapI site instead of AatII & This study \\
\hline 5'PrLasI & $\begin{array}{l}\text { GCGGATCCCGGACGTTTCTTC } \\
\text { GAGCCTAGCAAGG }\end{array}$ & $\begin{array}{l}5^{\prime} \text { promoter LasI primer with BamHI site, binds at nt } 1559133 \\
\text { of AE004091 }\end{array}$ & This study \\
\hline 3'PrLasI & $\begin{array}{l}\text { GCAAGCTTCGATCATCTTCACTTCCTCCAAAT } \\
\text { AGGAAGCTG }\end{array}$ & $\begin{array}{l}\text { 3' promoter LasI with HindIII site, binds at nt } 1559263 \text { of } \\
\text { AE004091 }\end{array}$ & This study \\
\hline $5^{\prime} \mathrm{LasRY} 56 \mathrm{~F}$ & $\begin{array}{l}\text { GCCTTCATCGTCGGCAACTTTCCGGCAGCCTG } \\
\text { GCGC }\end{array}$ & $\begin{array}{l}\text { Used with 3' complementary primer for creating Y56F } \\
\text { QuikChange mutagenesis (Stratagene) in LasR }\end{array}$ & This study \\
\hline 5'LasRW60F & $\begin{array}{l}\text { GCAACTACCCGGCAGCCTTTCGCGAGCATTAC } \\
\text { GACCG }\end{array}$ & $\begin{array}{l}\text { Used with } 3^{\prime} \text { complementary primer for creating W60F } \\
\text { QuikChange mutagenesis (Stratagene) in LasR }\end{array}$ & This study \\
\hline 5'LasRD73N & $\begin{array}{l}\text { GCTACGCGCGGGTCAATCCGACGGTCAGTCAC } \\
\text { TGTAC }\end{array}$ & $\begin{array}{l}\text { Used with } 3^{\prime} \text { complementary primer for creating D73N } \\
\text { QuikChange mutagenesis (Stratagene) in LasR }\end{array}$ & This study \\
\hline
\end{tabular}

${ }^{\mathrm{a}} \mathrm{nt}=$ nucleotide. 
LasR were carried out independently, with docking of 3-oxo$\mathrm{C}_{12}$-HSL as a control, using ZDOCK (Chen and Weng 2002) in its default global scanning mode.

\section{ACKNOWLEDGMENTS}

We thank J. S deRopp and W. T. Jewell for NMR and MS analyses, respectively; D. R. Cook for generously providing access to a microtiter plate reader; R. Jain, M. Krishnamurthy, C. Friday, C. Noriega, and Z Qamar for generous assistance; D. Hogan for induced culture filtrates; and R. Tsien for the td Tomato RFP strain. Support was provided by grants from the Ohio Plant Biotechnology Consortium (to W. D. Bauer and J. B. Robinson), NSF DEB-0120269 (to D. A. Phillips), National Research Initiative of the United States Department of Agriculture Cooperative State Research, Education and Extension 2003-01177 (to W. D. Bauer and J. B. Robinson), NRI 2004-03250 (to W. D. Bauer), NRI 2007-35319-18158 (to M. Teplitski, W. D. Bauer, and J. B. Robinson), and National Institute of Allergy and Infectious Disease R01-AI076272 (to E. C. Pesci).

\section{LITERATURE CITED}

Ahmer, B. M. 2004. Cell-to-cell signaling in Escherichia coli and Salmonella enterica. Mol. Microbiol. 52:933-945.

Arevalo-Ferro, C., Hentzer, M., Reil, G., Gorg, A., Kjelleberg, S., Givskov, M., Riedel, K., and Eberl, L. 2003. Identification of quorum-sensing regulated proteins in the opportunistic pathogen Pseudomonas aeruginosa by proteomics. Environ. Microbiol. 5:1350-1369.

Arevalo-Ferro, C., Reil, G., Gorg, A., Eberl, L., and Riedel, K. 2005. Biofilm formation of Pseudomonas putida IsoF: The role of quorum sensing as assessed by proteomics. Syst. Appl. Microbiol. 28:87-114.

Bacher, A., Eberhardt, S., Fischer, M., Kis, K., and Richter, G. 2000. Biosynthesis of vitamin b2 (riboflavin). Annu. Rev. Nutr. 20:153-167.

Bassler, B. L., and Losick, R. 2006. Bacterially speaking. Cell 125:237246.

Bertani, I., Rampioni, G., Leoni, L., and Venturi, V. 2007. The Pseudomonas putida Lon protease is involved in $\mathrm{N}$-acyl homoserine lactone quorum sensing regulation. BMC Microbiol. 7:71

Bjarnsholt, T., Jensen, P. O., Rasmussen, T. B., Christophersen, L., Calum, H., Hentzer, M., Hougen, H. P., Rygaard, J., Moser, C., Eberl, L., Hoiby, N., and Givskov, M. 2005. Garlic blocks quorum sensing and promotes rapid clearing of pulmonary Pseudomonas aeruginosa infections. Microbiology 151:3873-3880.

Bottomley, M. J., Muraglia, E., Bazzo, R., and Carfi, A. 2007. Molecular insights into quorum sensing in the human pathogen Pseudomonas aeruginosa from the structure of the virulence regulator LasR bound to its autoinducer. J. Biol. Chem. 282:13592-13600.

Brown, P., Hornbeck, C. L., and Cronin, J. R. 1972. Alloxazines and isoalloxazines. Mass spectromteric analysis of riboflavin and related compounds. Org. Mass Spectrom. 6:1383-1399.

Chen, R., and Weng, Z. 2002. Docking unbound proteins using shape complementarity, desolvation, and electrostatics. Proteins 47:281-94.

Degrassi, G., Devescovi, G., Solis, R., Steindler, L., and Venturi, V. 2007. Oryza sativa rice plants contain molecules that activate different quorum-sensing $\mathrm{N}$-acyl homoserine lactone biosensors and are sensitive to the specific AiiA lactonase. FEMS (Fed. Eur. Microbiol. Soc.) Microbiol. Lett. 269:213-220

de Kievit, T., Seed, P. C., Nezezon, J., Passador, L., and Iglewski, B. H. 1999. RsaL, a novel repressor of virulence gene expression in Pseudomonas aeruginosa. J. Bacteriol. 181:2175-2184.

Dong, H., and Beer, S. V. 2000. Riboflavin induces disease resistance in plants by activating a novel signal transduction pathway. Phytopathology 90:801-811.

Dong, Y. H., and Zhang, L. H. 2005. Quorum sensing and quorum-quenching enzymes. J. Microbiol. Spec. No. 43:101-109.

Foster, J. W., and Yanagita, T. 1956. A bacterial riboflavin hydrolase. J. Biol. Chem. 221:593-607.

Gao, M., Teplitski, M., Robinson, J. B., and Bauer, W. D. 2003. Production of substances by Medicago truncatula that affect bacterial quorum sensing. Mol. Plant-Microbe Interact. 16:827-834.

Gao, M., Chen, H., Eberhard, A., Gronquist, M. R., Robinson, J. B., Rolfe, B. G., and Bauer, W. D. 2005. sinI- and expR-dependent quorum sensing in Sinorhizobium meliloti. J. Bacteriol. 187:7931-7944.

Gao, M., Chen, H., Eberhard, A., Gronquist, M. R., Robinson, J. B., Connolly, M., Teplitski, M., Rolfe, B. G., and Bauer, W. D. 2007. Effects of AiiA-mediated quorum quenching in Sinorhizobium meliloti on quorum sensing signals, proteome patterns and symbiotic interactions. Mol. Plant-Microbe Interact. 20:843-856.

Givskov, M., de Nys, R., Manefield, M., Gram, L., Maximilien, R., Eberl,
L., Molin, S., Steinberg, P. D., and Kjelleberg, S. 1996. Eukaryotic interference with homoserine lactone-mediated prokaryotic signalling. J. Bacteriol. 178:6618-6622.

Glebova, G. D., Kirillova, N. I., and Berezovskii, V. N. 1977. Investigation in the alloxazine and isoalloxazine series XLVIII. Synthesis and properties of the 5-N-oxides and 5, 10-di-N-oxides of alloxazines. J. Org. Chem. USSR (Engl. Transl.) 13:996-1001.

Harris, E. H. 1989. The Chlamydomonas Sourcebook. Academic Press, San Diego, CA

Holden, M. T., Ram Chhabra, S., de Nys, R., Stead, P., Bainton, N. J., Hill, P. J., Manefield, M., Kumar, N., Labatte, M., England, D., Rice, S., Givskov, M., Salmond, G. P., Stewart, G. S., Bycroft, B. W., Kjelleberg, S., and Williams, P. 1999. Quorum-sensing cross talk: Isolation and chemical characterization of cyclic dipeptides from Pseudomonas aeruginosa and other gram-negative bacteria. Mol. Microbiol. 33:12541266

Joseph, C. M., and Phillips, D. A. 2003. Metabolites from soil bacteria affect plant water relations. Plant Physiol. Biochem. 41:189-192.

Karamanoli, K., and Lindow, S. E. 2006. Disruption of $N$-acyl homoserine lactone-mediated cell signaling and iron acquisition in epiphytic bacteria by leaf surface compounds. Appl. Environ. Microbiol. 72:76787686

Khan, W., Prithiviraj, B., and Smith, D. L. Nod factor [Nod Bj V (C(18:1), $\mathrm{MeFuc})]$ and lumichrome enhance photosynthesis and growth of corn and soybean. J. Plant Physiol. In press.

Koch, B., Liljefors, T., Persson, T., Nielsen, J., Kjelleberg, S., and Givskov, M. 2005. The LuxR receptor: The sites of interaction with quorum-sensing signals and inhibitors. Microbiology 151:3589-3602.

Kovach, M. E., Elzer, P. H., Hill, D. S., Robertson, G. T., Farris, M. A., Roop, R. M., 2nd, and Peterson, K. M. 1995. Four new derivatives of the broad-host-range cloning vector pBBR1MCS, carrying different antibiotic-resistance cassettes. Gene 166:175-176.

Kumar, S. A., and Vaidyanathan, C. S. 1964. Hydrolysis of riboflavin in plants. Biochim. Biophys. Acta 89:127-136.

Lee, J., Jayaraman, A., and Wood, T. K. 2007. Indole is an inter-species biofilm signal mediated by SdiA. BMC Microbiol. 7:42.

Manefield, M., Rasmussen, T. B., Henzter, M., Andersen, J. B., Steinberg, Kjelleberg, P. S., and Givskov, M. 2002. Halogenated furanones inhibit quorum sensing through accelerated LuxR turnover. Microbiology 148:1119-1127.

Matiru, V. N., and Dakora, F. D. 2005a. The rhizosphere signal molecule lumichrome alters seedling development in both legumes and cereals. New Phytol. 166:439-444.

Matiru, V. N., and Dakora, F. D. 2005b. Xylem transport and shoot accumulation of lumichrome, a newly recognized rhizobial signal, alters root respiration, stomatal conductance, leaf transpiration and photosynthetic rates in legumes and cereals. New Phytol. 165:847-855.

Meade, H. M., and Signer, E. R. 1977. Genetic mapping of Rhizobium meliloti. Proc. Natl. Acad. Sci. U.S.A. 74:2076-2078.

Muh, U., Schuster, M., Heim, R., Singh, A., Olson, E. R., and Greenberg, E. P. 2006a. Novel Pseudomonas aeruginosa quorum-sensing inhibitors identified in an ultra-high-throughput screen. Antimicrob. Agents Chemother. 50:3674-3679.

Muh, U., Hare, B. J., Duerkop, B. A., Schuster, M., Hanzelka, B. L., Heim, R., Olson, E. R., and Greenberg, E. P. 2006b. A structurally unrelated mimic of a Pseudomonas aeruginosa acyl-homoserine lactone quorum-sensing signal. Proc. Natl. Acad. Sci. U.S.A. 103:16948-16952.

Pearson, J. P., Pesci, E. C., and Iglewski, B. H. 1997. Roles of Pseudomonas aeruginosa las and $r h l$ quorum-sensing systems in control of elastase and rhamnolipid biosynthesis genes. J. Bacteriol. 179:5756-5767.

Persson, T., Hansen, T. H., Rasmussen, T. B., Skinderso, M. E., Givskov, M., and Nielsen, J. 2005. Rational design and synthesis of new quorumsensing inhibitors derived from acylated homoserine lactones and natural products from garlic. Org. Biomol. Chem. 3:253-262.

Phillips, D. A., Joseph, C. M., Yang, G. P., Martínez-Romero, E., Sanborn, J. R., and Volpin, H. 1999. Identification of lumichrome as a Sinorhizobium enhancer of alfalfa root respiration and shoot growth. Proc. Natl. Acad. Sci. U.S.A. 96:12275-12280.

Phillips, D. A., Martínez-Romero, E., Yang, G., and Joseph, C. M. 2000. Release of nitrogen: A key trait in selecting bacterial endophytes for agronomically useful nitrogen fixation. Pages 205-217 in: The Quest for Nitrogen Fixation in Rice. P. M. R. J. K. Ladha, ed. International Rice Research Institute, Makati City, Philippines.

Rampioni, G., Bertani, I., Zennaro, E., Polticelli, F., Venturi, V., and Leoni, L. 2006. The quorum-sensing negative regulator RsaL of Pseudomonas aeruginosa binds to the lasI promoter. J. Bacteriol. 188:815-819.

Rasmussen, T. B., and Givskov, M. 2006. Quorum sensing inhibitors: A bargain of effects. Microbiology 152:895-904.

Riedel, K., Kothe, M. Kramer, B., Saeb, W., Gotschlich, A., Ammendola, A., and Eberl, L. 2006. Computer-aided design of agents that inhibit the 
cep quorum-sensing system of Burkholderia cenocepacia. Antimicrob. Agents Chemother. 50:318-323.

Shaner, N. C., Campbell, R. E., Steinbach, P. A., Giepmans, B. N., Palmer, A. E., and Tsien, R. Y. 2004. Improved monomeric red, orange and yellow fluorescent proteins derived from Discosoma sp. red fluorescent protein. Nat. Biotechnol. 22:1567-1572.

Steidle, A., Sigl, K., Schuhegger, R., Ihring, A., Schmid, M., Gantner, S., Stoffels, M., Riedel, K., Givskov, M., Hartmann, A., Langebartels, C., and Eberl, L. 2001. Visualization of $\mathrm{N}$-acylhomoserine lactone-mediated cell-cell communication between bacteria colonizing the tomato rhizosphere. Appl. Environ. Microbiol. 67:5761-5770.

Teplitski, M., Robinson, J. B., and Bauer, W. D. 2000. Plants secrete substances that mimic bacterial $N$-acyl homoserine lactone signal activities and affect population density-dependent behaviors in associated bacteria. Mol. Plant-Microbe Interact. 13:637-648.

Teplitski, M., Chen, H., Rajamani, S., Gao, M., Merighi, M., Sayre, R. T., Robinson, J. B., Rolfe, B. G., and Bauer, W. D. 2004. Chlamydomonas reinhardtii secretes compounds that mimic bacterial signals and interfere with quorum sensing regulation in bacteria. Plant Physiol. 134:137146.

Tsukamoto, S., Kato, H., Hirota, H., and Fusetani, N. 1999. Lumichrome. A larval metamorphosis-inducing substance in the ascidian Halocynthia roretzi. Eur. J. Biochem. 264:785-789.

Vannini, A., Volpari, C., Gargioli, C., Muraglia, E., Cortese, R., De
Francesco, R., Neddermann, P., and Marco, S. D. 2002. The crystal structure of the quorum sensing protein TraR bound to its autoinducer and target DNA. EMBO (Eur. Mol. Biol. Organ.) J 21:4393-4401.

Vasil, M. L. 2003. DNA microarrays in analysis of quorum sensing: Strengths and limitations. J. Bacteriol. 185:2061-2065.

Wade, D. S., Calfee, M. W., Rocha, E. R., Ling, E. A., Engstrom, E., Coleman, J. P., and Pesci, E. C. 2005. Regulation of Pseudomonas quinolone signal synthesis in Pseudomonas aeruginosa. J. Bacteriol. 187:4372-4380.

Winson, M. K., Swift, S., Fish, L., Throup, J. P., Jorgensen, F., Chhabra, S. R., Bycroft, B. W., Williams, P., and Stewart, G. S. 1998. Construction and analysis of luxCDABE-based plasmid sensors for investigating $\mathrm{N}$ acyl homoserine lactone-mediated quorum sensing. FEMS (Fed. Eur. Microbiol. Soc.) Microbiol. Lett. 163:185-192.

Xiao, S., Dai, L., Liu, F., Wang, Z., Peng, W., and Xie, D. 2004. COS1: An Arabidopsis coronatine insensitive1 suppressor essential for regulation of jasmonate-mediated plant defense and senescence. Plant Cell 16:1132-1142.

Yang, C. S., and McCormick, D. B. 1967. Substrate specificity of riboflavin hydrolase from Pseudomonas riboflavina. Biochim. Biophys. Acta 132:511-513.

Zhang, H. B., Wang, L. H., and Zhang, L. H. 2002. Genetic control of quorum-sensing signal turnover in Agrobacterium tumefaciens. Proc. Natl. Acad. Sci. U.S.A. 99:4638-4643. 